\title{
МАРКЕТИНГОВОЕ ИССЛЕДОВАНИЕ ПОРТРЕТА ПОТРЕБИТЕЛЕЙ УСЛУГ СЕЛЬСКОГО ЗЕЛЕНОГО ТУРИЗМА
}

\begin{abstract}
В статье проведено исследование существующих подходов к сегментации потребителей услуг сельского зеленого туризма и представлены результаты собственного маркетингового исследования с целью формирования социальнопсихологического портрета потребителей услуг сельского зеленого туризма.

В статье обосновано, что социально-психологический портрет потребителя услуг сельского зеленого туризма следующий - это житель большого города среднего возраста, которого привлекает непосредственный контакт с богатством национальной истории, фольклора, традиционными занятиями и народными обычаями, которые превращают сельские отпуска в настоящий процесс ассимиляции новых и многочисленных знаний и обретение навыков, которые приносят туристам личные сатисфакции и ощущение единства и возможность лечения свежим воздухом и фруктами, употребление свежих экологически чистых продуктов. Среди туристических услуг, которые желает получить потребитель от данного вида туризма есть такие, что непосредственно связанны с народной гостеприимностью, кулинарными обычаями, сельскими народными ремеслами и ритуалами, которые заставляют туристов познать на местном уровне и сохранять продолжительные воспоминания из необыкновенных отпусков. Потребители услуг сельского зеленого туризма воспринимают его как демократичесий по расходам вид отдыха, который несет в большей мере культурное обогащение и моральный комфорт. В то же время, потребители воспринимают сельский зеленый туризм как экономически удобный вид отдыха и готовы платить за данные туристические услуги демократическую цену. Установленные социальнопсихологические особенности потребителей услуг сельского зеленого туризма позволят владельцам усадеб разработать наиболее эффективную политику формирования туристического продукта и его продвижения на рынок.

Ключевые слова: сельский зеленый туризм, сегментация потребителей, маркетинговое исследование, мотивация потребителей, портрет потребителей.
\end{abstract}

Одним из препятствий на пути эффективного продвижения продукта сельского зеленого туризма является отсутствие профессионально сформированной коммуникационной политики. Также, по мнению ряда специалистов, значительное количество туристических маршрутов и продуктов разработаны почти при отсутствии информации о настоящих нуждах клиентов, так как в Украине не проводились фундаментальные исследования и сегментация потребителей туристического продукта сельского зеленого туризма, а существующие не

\footnotetext{
${ }^{1}$ Dr hab. Zaburanna Lesia Valentinovna, associate professor of Managment Department of National University of Life and Environmental Sciences of Ukraine, 5B Basseynaya Str, Apt 31 Kyiv, Ukraine 01004, e-mail: alesenka2003@ukr.net.
} 
удовлетворяют требования относительно формирования реального профиля потребителя туристического продукта данного вида туризма.

Маркетинговым исследованием потребителей в туристической деятельности посвящены работы ряда отечественных и зарубежных исследователей: Азара В.И., Ансоффа И., Багиева Г.Л., Базела Р.Д., Биржакова М.Б., Болта Г.Дж., Ветитнева А.М., Войчака А.В., Герасименко В.Г., Герасимчука В.И., Джеффриса П., Дуровича А.Г., Квартальнова В.А., Котлера Ф., Сапрунова В.Б., Ткаченко Т.И., Шульгиной Л.Н. и других. Непосредственно исследованию потребителей услуг сельского зеленого туризма посвящены работы Кудиновой И.П., Мазуркевича Л., Рутинского Н.Й., Зинько Ю.В. и других. Тем не менее, данные исследования не дают полной информации о демографических, психологических и поведенческих характеристиках потребителей услуг сельского зеленого туризма, что и обусловило необходимость проведения маркетингового исследования.

Целью научной статьи является определение социально-психологического портрета потребителей услуг сельского зеленого туризма для формирования эффективной политики маркетинговых коммуникаций владельцами сельских усадеб.

Существует несколько подходов к проблеме сегментирования рынка в сфере сельского зеленого туризма. Польский ученый Л. Мазуркевич выделяет семь сегментов агротуристического рынка на основе учета основных требований потребителей: «обособленники», «семейные», «собиратели», «охотники», «ездоки», «велосипедисты» и «нервные» [9]. К сожалению, данный подход не учитывает ряд экономических и психографических особенностей потенциальных потребителей агротуристических услуг.

Отечественные ученые Н.Й. Рутинский и Ю.В. Зинько определяют три потенциальные сегмента потребителей агротуристического продукта: городские жители, люди творческого и умственного труда, а также иностранцы [5]. На наш взгляд, данная классификация является чрезвычайно широкой и не учитывает необходимости индивидуального подхода к формированию туристического предложения в данной сфере.

Ученая И.П. Кудинова считает, что сегодня в Украине основные сегменты потенциальных потребителей услуг сельского зеленого туризма образуют: жители промышленных центров, настоящие горожане, почитатели украинских народных традиций и люди с малым и средним благосостоянием [2]. Мы считаем, что в данном делении целесообразно выделить более узкие сегменты потребителей с учетом их требований и поведенческих характеристик.

Целью проведенного нами в сентябре-январе 2012-2013 г.г. социологического опроса потребителей услуг сельского зеленого туризма было формирование их социально-психологического портрета. Опросом были охвачены 151 респондент жители Украины, которые воспользовались или планируют воспользоваться услугами сельского зеленого туризма. Исследование проводилось путем анкетного опроса, интервью и длительного визуального наблюдения. Вопросы в анкете формировались таким образом, чтобы определить и соотнести основные социальнопсихологические и демографические характеристики потребителей с их денежными тратами на услуги сельского зеленого туризму. Расчет объема выборки с помощью $\mathrm{t}$-статистики Стьюдента показал, что оптимальное количесво респондентов 
составляет 151 человек. При построении выборки привлекались ресурсы Интернет, данные Союза содействия зеленому туризму в Украине, личные контакты.

Для более детального исследования мотиваций потребителей услуг сельского зеленого туризма согласно регионам проживания, мы провели анализ количества полученных анкет в разрезе десяти экономических районов Украины (рис.1):

1. Донецкий (Донецкая и Луганская обл.);

2. Приднепровский (Днепропетровская и Запорожская обл.);

3. Северо-Восточный (Харьковская, Полтавская и Сумская обл.);

4. Столичный (Киевская, Черниговская и Житомирская обл.);

5. Центральный (Черкасская и Кировоградская обл.);

6. Подольский (Винницкая, Хмельницкая и Тернопольская обл.);

7. Северо-Западный (Волынская и Ровенская обл.);

8. Карпатский (Львовская, Ивано-Франковская, Закарпатская и Черновецкая обл.);

9. Причерноморский (Одесская, Николаевская и Херсонская обл.);

10. Автономная Республика Крым и Севастополь (горсовет).

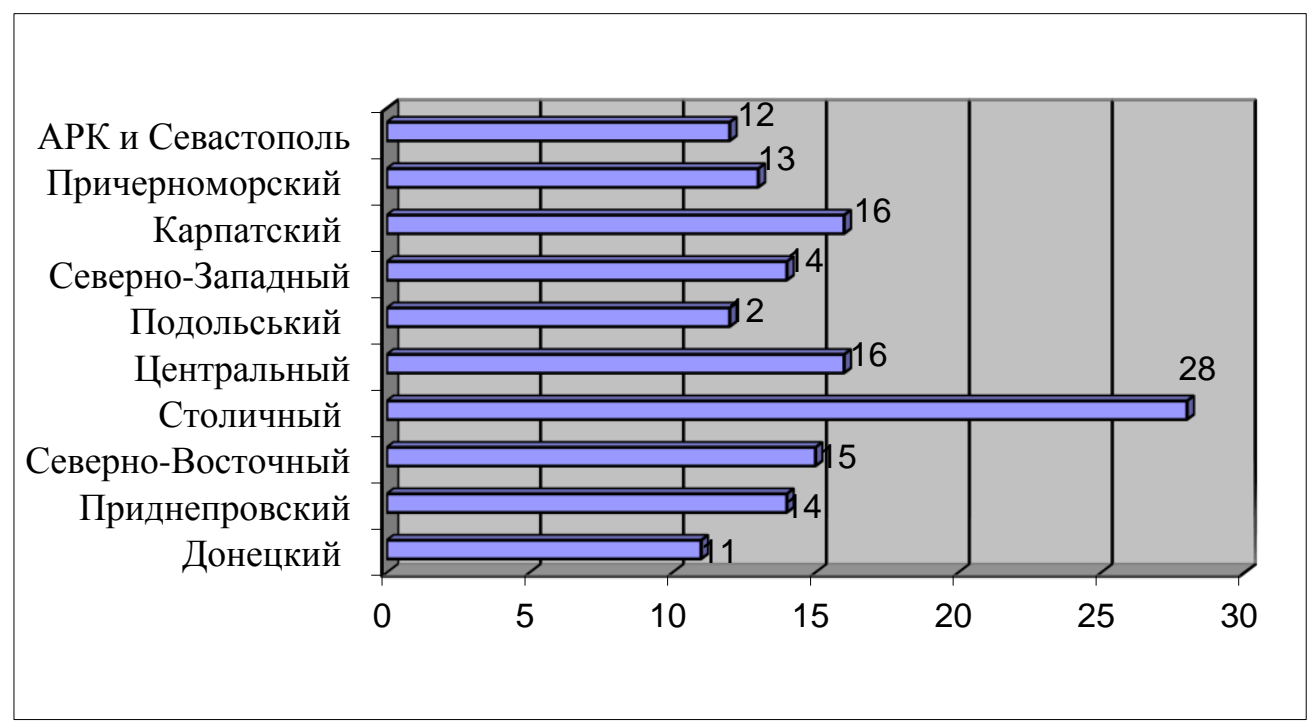

Рис. 1. Распределение опрошенных респондентов по экономическим районам Украины, чел.

Результаты анализа свидетельствуют, что наибольшее количество опрошенных проживает в Столичном регионе, который отвечает рациональным желаниям жителей большого мегаполиса приобщиться к отдыху в экологически чистых местностях с национальным колоритом.

Анализу мотивационных характеристик предшествовало детальное рассмотрение состава опрошенных. В частности, половозрастная структура представлена в табл. 1.

Как видно из данных таблицы 1 , среди опрошенных преобладают мужчины $66,6 \%$, что свидетельствует в пользу большей склонности этого пола к принятию решения относительно выбора способа и места отдыха. Отсутствуют женщины 
среди опрошенных в категории старше 51 лет. Это исчерпывающе объясняет сформированное распределение и дальнейшую динамику ответов респондентов.

Таблица 1. Данные об опрошенных потребителях услуг сельского зеленого туризма

\begin{tabular}{|c|c|c|c|c|c|c|}
\hline \multirow{2}{*}{ Показатели } & \multicolumn{2}{|c|}{ Всего } & \multicolumn{3}{c|}{ В том числе } \\
\cline { 2 - 6 } & \multicolumn{2}{|c|}{$\begin{array}{c}\text { Количество, } \\
\text { чел. }\end{array}$} & $\%$ & $\begin{array}{c}\text { Количество, } \\
\text { чел. }\end{array}$ & $\%$ & $\begin{array}{c}\text { Количество, } \\
\text { чел. }\end{array}$ \\
\hline $\begin{array}{c}\text { Опрошено } \\
\text { всего: }\end{array}$ & 151 & 100 & 101 & 66,6 & 50 & 33,4 \\
\hline $\begin{array}{c}\text { в т.ч. по } \\
\text { возрасту, лет }\end{array}$ & 15 & 9,85 & 17 & 16,83 & 3 & 6 \\
\hline $18-30$ & 67 & 44,41 & 41 & 40,59 & 23 & 46 \\
\hline $31-40$ & 58 & 38,50 & 33 & 32,67 & 24 & 48 \\
\hline $41-50$ & 11 & 7,23 & 10 & 9,90 & - & 0 \\
\hline 51 и больше & & & & & \\
\hline
\end{tabular}

Следует отметить, что 44,41 \% опрошенных - это наибольшая группа в возрасте 31-40 лет и характеризуются, с одной стороны, наличием определенного опыта в выборе способа и места отдыха, наличием семьи и детей, а с другого наименьшим сопротивлением изменениям, способностью интересоваться новым нетрадиционными видами туризма, приобщаться к разнообразным мероприятиям и способам досуга, желанием отдыхать в экологически чистых местностях после изнурительной офисной работы в мегаполисах. Также значительной является группа в возрасте 41-50 лет, которая характеризуется наличием уже повзрослевших детей, которых родители стремятся приобщать к истокам украинской культуры и быта, а также стремлением к собственному духовному саморазвитию на базе изучения национальных особенностей, истории и традиций.

Вышеприведенные факты подтверждаются также ответами на вопрос относительно преимущества в выборе места отдыха и мотивации для использования услуг усадеб сельского зеленого туризма. Подавляющее большинство опрошенных предпочитает отдых в сельских территориях Украины $(47,05 \%)$ и с палаткой $(25,5 \%)$, что свидетельствует о значительном стремлении объединения отдыха с культурным обогащением и важности экологической составляющей (рис. 2). 


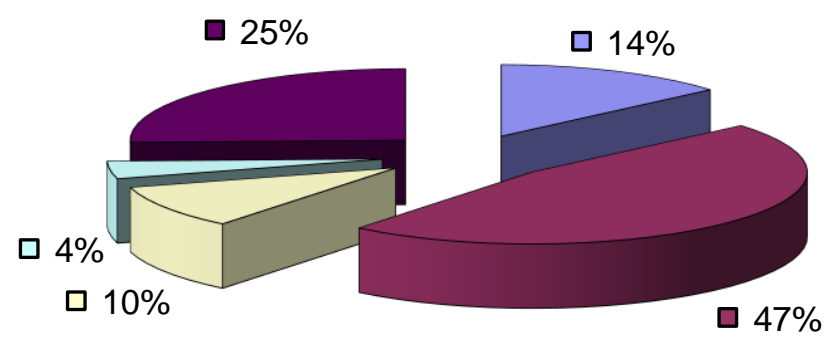

口В своей стране на берегу моря

$\square$ В своей стране на сельских территориях

口Зарубежом

口Дома

口С палаткой

Рис. 2. Распределение опрошенных относительно преимущества в выборе места отдыха, \%

Нами определено, что в формировании спроса на отдых в сельской местности наибольшее влияние оказывает индустриализация страны, возникновение у людей необходимости не потреблять больше товаров, а получить больше «живых впечатлений и опыта» (путешествия, которые оказывают содействие личному росту и обогащению знаниями о культуре и природе), а также рост заботы о здоровье и поддержании физической формы - активный отдых на открытом воздухе. Лишь четвертое место для потребителей услуг сельского зеленого туризма занимают экономические факторы (рис. 3).

В процессе исследования выяснено, что наиболее популярными туристическими услугами в сфере сельского зеленого туризма являются те, котороые связаны с осуществлением различных туристических программ (этнографические фестивали, вечерницы, народные обряды) и знакомством с местной культурой и бытом (в пользу этих видов услуг высказались 82\% и 89\% опрошенных). 


\section{3}

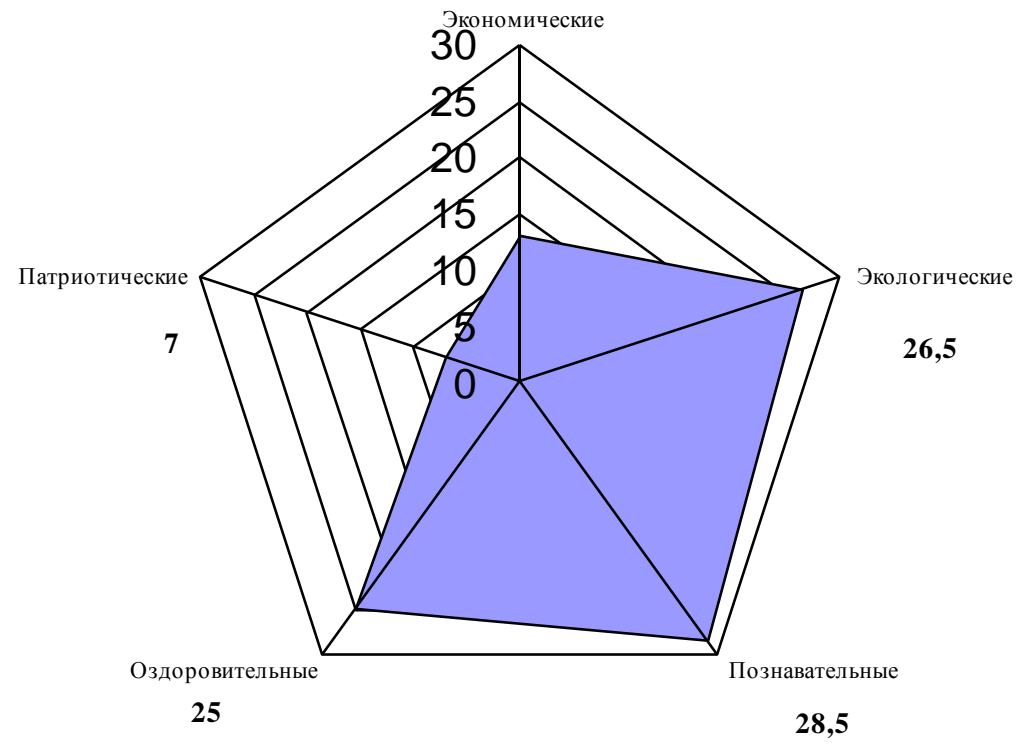

Рис. 3. Распределение опрошенных по ответу на вопрос «Какие мотивы побуждали Вас воспользоваться услугами усадеб сельского туризма?», \%

Также большое значение приобретают тишина и незагрязненная окружающая среда как главнейшие выгоды от отдыха в сельской местности, важность которых указали $78 \%$ опрошенных.

Значительное распространение приобрели оздоровительные сауны с фиточаями, зимние развлечения с катанием на санях. В ряде областей Украины распространены сбор ягод и грибов, квалифицированный туризм (пешие, конные прогулки). В то же время, традиционные выгоды туризма (размещение, питание) имеют второстепенное значение. 


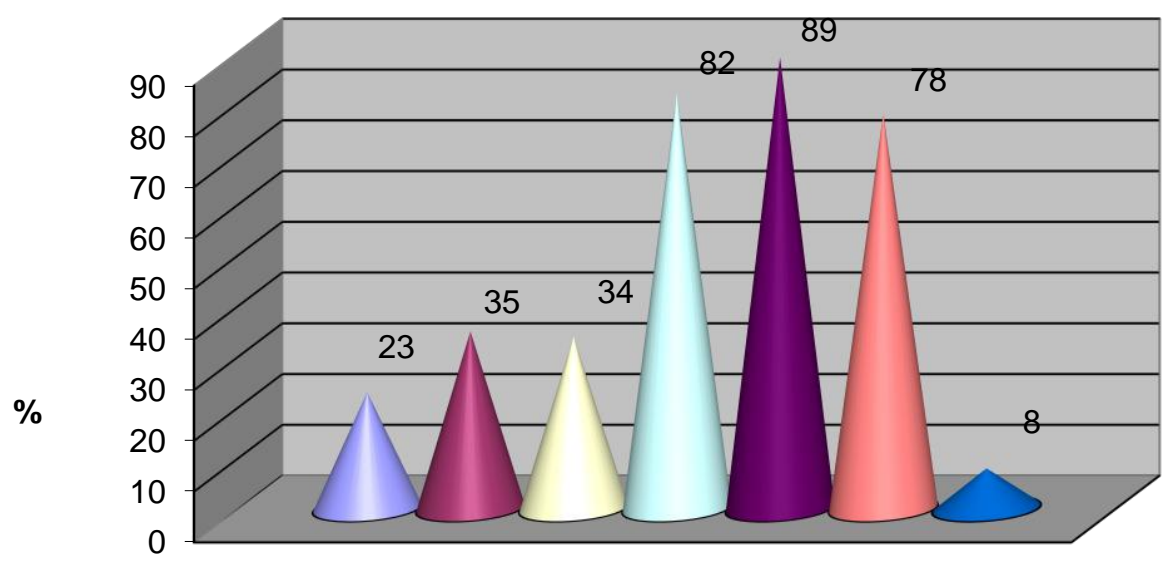

口Комфортабельное размещение

口Питание

口Развлечения

口Тур-программы (экскурсии, поход в горы, этнографические мероприятия и т.д.)

-Знакомство с местной культурой и бытом

口Отдых в красочной и экологически чистой местности

口Другое

Рис. 4. Распределение опрошенных по ответу на вопрос «Какие услуги в усадьбах сельского туризма для Вас наиболее важны?», \%

Итак, отдых в селах привлекает, прежде всего, жителей больших городов, которые хотят пожить хотя бы некоторое время в экологически чистой местности, полакомиться натуральными продуктами традиционной украинской кухни, немного отдохнуть от интенсивной городской жизни в сельской усадьбе. Туристов привлекает в село на отдых определенная экзотика сельской работы, горожане хотят показать своим детям, откуда берутся хлеб, молоко и другие продукты. Также, туристов привлекает в селе возможность покататься на лошадях, порыбачить, поохотиться, покататься на бричках или санях, прогулки на лодках, катерах и яхтах, участие в традиционных народных праздниках, сельских свадьбах. Гости сельской местности с удовольствием покупают сувениры, изделия народных мастеров. Они хотят приобрести подарки для своих знакомых или взять что-то на память о посещенной местности. Для местной общины продажа сувениров и изделий народных промыслов может быть источником прибыли, а также средством рекламы своего туристического потенциала. 
Что касается формирования ценовой политики владельцами усадеб сельского зеленого туризма, то тут следует обратить внимание на распределение опрошенных в ответе на вопрос «Какую ценовую категорию сельских усадеб Вы бы избрали для отдыха (чел./сутки)?» (рис. 5). Как видно, потребители услуг сельского зеленого туризма предпочитают политику демократичного ценообразования и большинство из них готовы платить до 100 грн. в сутки за человека.

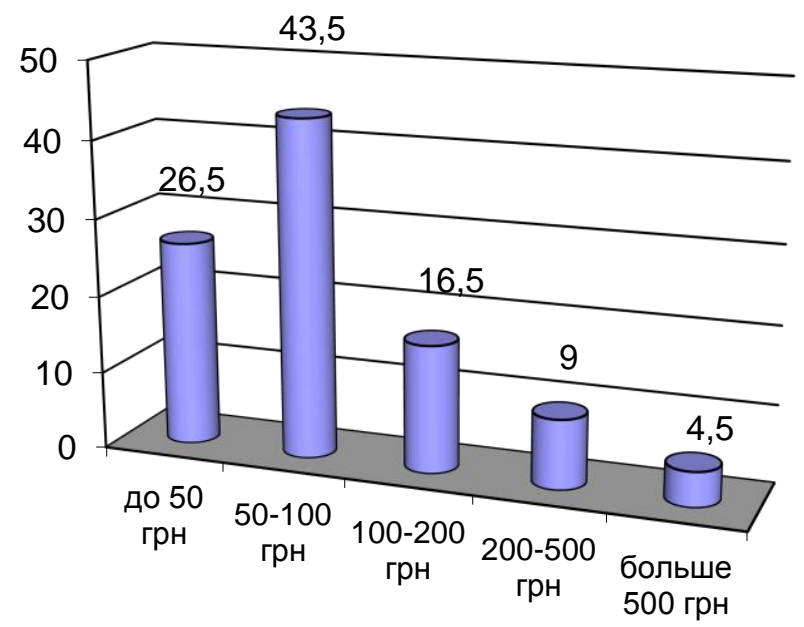

Рис. 5. Распределение опрошенных по ответу на вопрос «Какую ценовую категорию сельских усадеб Вы бы избрали для отдыха (чел./сутки)?», \%

Эти данные свидетельствуют о том, что потребители воспринимают услуги сельского зеленого туризма как демократический по расходам вид отдыха, который несет в большей мере культурное обогащение и моральный комфорт.

Итак, в процессе исследования установлен следующий социальнопсихологический портрет потребителя услуг сельского зеленого туризма - это житель большого города среднего возраста, которого привлекает непосредственный контакт с богатством национальной истории, фольклора, традиционными занятиями и народными обычаями, которые превращают сельские отпуска в настоящий процесс ассимиляции новых многочисленных знаний и обретения навыков, приносящих туристам личные сатисфакции и ощущение единства, а также возможность лечения свежим воздухом и фруктами, употребления свежих экологически чистых продуктов. Среди туристических услуг, которые желает получить потребитель от данного вида туризма есть непосредственно связанные с народной гостеприимностью, кулинарными обычаями, сельскими народными ремеслами и ритуалами, которые заставляют туристов сохранять продолжительные воспоминания из необыкновенных отпусков. В то же время, потребители воспринимают сельский зеленый туризм как экономически удобный вид отдыха 
и готовы платить за данные туристические услуги демократичную цену. Установленные нами социально-психологические особенности потребителей услуг сельского зеленого туризма позволят владельцам усадеб разработать наиболее эффективную политику формирования туристического продукта и его продвижения на рынок.

\section{ЛИТЕРАТУРА}

[1] Квартальнов В.А. Туризм / В.А. Квартальнов. - М.: Финансы и статистика, 2002. - 320 с.

[2] Кудінова, І.П., Породько, М.А. [Текст] Соціально-економічне значення та проблеми розвитку сільського зеленого туризму в Україні // І.П. Кудінова, М.А.Породько / Збірник статей міжнародної школи-семінару “Теорія i практика інноваційноконсультаційної діяльності” - К.: Видавничий центр НУБіП України, 2010. - С. 169-171.

[3] Дурович А.П. Маркетинг в туризме / А.П. Дурович. - Минск: Новое знание, 2003. - 496 с.

[4] Малхотра, Нэреш К. Маркетинговые исследования. Практическое руководство, 3-е издание: Пер. с англ. / Малхотра, Нэреш К. - М.: Издательский дом «Вильямс», 2002. $960 \mathrm{c}$.

[5] Рутинський, М.Й. Сільський туризм [Текст] : навчальний посібник / М. Й. Рутинський, Ю. В. Зінько. - Київ : Знання, 2006. - 271 с.

[6] Хамидова О.М. Методические рекомендации по усовершенствованию методики маркетинговых исследований в туризме и оценки конкурентоспособности туристических услуг / О.М. Хамидова. - Симферополь: Крымский институт Киевского национального экономического университета, 2003. - 52 с.

[7] Цёхла С.Ю. Направление совершенствования маркетинговых исследований крымского турпродукта / С. Ю. Цёхла, Е.Н. Бобарыкина // Экономика и управление. - 2002. - № 6. - C. 31-35.

[8] Шульгіна Л.М. Маркетинг підприємств туристичного бізнесу: монографія / Шульгіна Л.М. - К.: Київ. нац. торг.-екон. ун-т, 2005. - 597 с.

[9] Mazurkiewicz L. Planowanie marketingowe w przedsiebiorstwie turystycznym. - Warszawa, 2002. -404 s.

\section{BADANIA MARKETINGOWE PROFILU NABYWCÓW USŁUG AGRO- TURYSTYKI}

W niniejszej pracy przeanalizowano istniejące podejścia do segmentacji konsumentów agroturystyki oraz przedstawiono wyniki własnych badań rynku w celu stworzenia społecznego i psychologicznego profilu konsumentów agroturystyki.

$\mathrm{W}$ artykule przedstawiono społeczny i psychologiczny profil nabywcy usług agroturystycznych. Jest to mieszkaniec miasta, w średnim wieku, zapoznany z bogactwem historii narodu, folklorem, obyczajami ludowymi, co sprawia, że agroturystyka w procesie asymilacji i nabywania wiedzy i umiejętności doprowadza turystów do osobistej satysfakcji i poczucia jedności. Wśród usług turystycznych są też takie, które są bezpośrednio związane z gościnnością ludzi, tradycjami kulinarnymi, rękodziełem i rytuałami, które sprawiają, że turyści mają niezwyłe wspomnienia $\mathrm{z}$ urlopu. Jednocześnie konsumenci postrzegają agroturystykę jako przyjazną kosztowo formę rekreacji. Zestaw społeczno-psychologicznych cech konsumentów gospodarstw agroturystycznych umożliwia właścicielom rozwijać najbardziej efektywne tworzenie polityki i produktu turystycznego na rynku.

Słowa kluczowe: agroturystyka, segmentacja konsumentów, badania marketingowe, motywacja konsumentów, profile konsumentów. 


\section{MARKETING RESEARCH OF PURCHASERS OF GREEN TOURISM SERVICES}

The article deals with the research of the existing approaches to segmentation of consumers of rural green tourism and the results of its own market research in order to create social and psychological portrait of the consumers of rural green tourism.

The article proved that the social and psychological portrait of the consumer services of rural green tourism is following - a resident of the city of middle age, who involves direct contact with the wealth of the nation's history, folklore, traditional occupations and folk customs, who makes rural holiday in a real process of assimilation of new and numerous knowledge and the acquisition of skills that bring tourists to personal satisfaction and a sense of unity and the ability to treat the fresh air and fruit consumption of fresh organic produce. Among the tourist services that the consumer wants to get from this type of tourism there are some that are directly attributable to people's hospitality, culinary traditions, rural handicrafts and rituals that make tourists know at the local level and to maintain long-lasting memories of unusual holidays. Customers of rural green tourism perceive it as a democratic form of recreation for the costs, which is increasingly the cultural enrichment and moral comfort. At the same time, consumers perceive green rural tourism as a cost- friendly form of recreation, and are willing to pay for these travel services democratic price. Set of socio- psychological characteristics of consumers of rural tourism homesteads allow owners to develop the most effective policy formation and its tourism product to market.

Keywords: rural green tourism, consumer segmentation, marketing research, consumer motivation, portrait consumers.

DOI: 10.7862/rz.2013.mmr.12

Teks złożono w redakcji: luty 2013

Przyjęto do druku: czerwiec 2013 